\title{
Environmental risk assessments for transgenic crops producing output trait enzymes
}

\author{
Alan Raybould $\cdot$ Ann Tuttle $\cdot$ Scott Shore $\cdot$ \\ Terry Stone
}

Received: 29 June 2009/Accepted: 30 October 2009/Published online: 19 November 2009

(C) The Author(s) 2009. This article is published with open access at Springerlink.com

\begin{abstract}
The environmental risks from cultivating crops producing output trait enzymes can be rigorously assessed by testing conservative risk hypotheses of no harm to endpoints such as the abundance of wildlife, crop yield and the rate of degradation of crop residues in soil. These hypotheses can be tested with data from many sources, including evaluations of the agronomic performance and nutritional quality of the crop made during product development, and information from the scientific literature on the mode-of-action, taxonomic distribution and environmental fate of the enzyme. Few, if any, specific ecotoxicology or environmental fate studies are needed. The effective use of existing data means that regulatory decision-making, to which an environmental risk assessment provides essential information, is not unnecessarily complicated by evaluation of large amounts of new data that provide negligible improvement in the characterization of risk, and that may delay environmental benefits offered by transgenic crops containing output trait enzymes.
\end{abstract}

\footnotetext{
A. Raybould ( $\square)$

Syngenta, Jealott's Hill International Research Centre, Bracknell, Berkshire RG42 6EY, UK

e-mail: alan.raybould@syngenta.com
}

\section{A. Tuttle $\cdot$ S. Shore $\cdot$ T. Stone}

Syngenta Biotechnology Incorporated, PO Box 12257, 3054 East Cornwallis Road, Research Triangle Park, NC 27709-2257, USA
Keywords Risk assessment . Problem formulation - Hypothesis testing · Output traits · Event 3272 maize

\section{Introduction}

Transgenic crops with enhanced resistance to insect pests or tolerance of broad-spectrum herbicides have been commercially available for over a decade and are widely used worldwide. Insect resistance and herbicide tolerance are examples of "input traits", which improve the agronomic performance of the crop. Transgenic crops with "output traits", which improve the quality of the crop for the customer, are now being commercialised. Some output traits are based on the production of one or a few additional enzymes which are the ultimate product or desired phenotype of the transgenic plant. Such enzymes may improve the processing of plant polymers, such as lignin, cellulose, hemicellulose and starch, so that the crop has increased value as a source of biofuels (Lynd et al. 1999; Oraby et al. 2007; Ragauskas et al. 2006; Sticklen 2006, 2008), or may improve the nutritional quality of crops for human and animal food and feed, for example by increasing the availability of nutrients such as phosphate (Bouis et al. 2003; Flachowsky et al. 2005). Enzymes that are valuable per se, rather than because they alter 
plant metabolism to produce a useful phenotype, may be termed "output trait enzymes".

Commercial development of transgenic crops producing output trait enzymes requires suitable methods for environmental risk assessment ${ }^{1}$ to meet regulatory requirements in a timely and cost-effective fashion (Chapotin and Wolt 2007). This paper describes a framework that provides rigorous environmental risk assessments of transgenic crops producing output trait enzymes. Aspects of the framework are illustrated by its application to transgenic Event 3272 maize, which produces a chimeric heat-stable alpha-amylase (AMY797E) in its grain. AMY797E improves the processing of corn starch for ethanol production, and inclusion of Event 3272 grain in batches of grain for dry-grind ethanol production can remove the need for exogenous heat-stable alphaamylases (Singh et al. 2006). Event 3272 maize also contains phosphomannose isomerase as a selectable marker. The environmental risks of this protein have been evaluated elsewhere and determined to be minimal (Reed et al. 2001; Privalle 2002; US EPA 2004) and will not be considered in this paper.

The methods to assess the environmental risks posed by cultivation of Event 3272 maize are considered relevant to other transgenic crops in which the presence of an additional enzyme is the output trait. Similar principles may apply to the risk assessment of transgenic plants in which production of additional enzymes is the means by which a output trait is achieved, for example the expression of enzymes that alter the fatty acid composition of seeds (Napier 2007); however, when enzymes are the means not the ends, more emphasis may need to be placed on potentially harmful pleiotropic effects of manipulating plant metabolism than on characterisation of potentially harmful effects of the enzymes themselves.

\footnotetext{
$\overline{1}$ In assessments of transgenic crops, the term "environmental risk" tends to be used narrowly and refers to potential harm to organisms or biological processes from direct interactions with the crop (termed "ecological risk" in some regulatory systems). This paper uses environmental risk in this narrow sense and therefore does not consider wider environmental questions posed by the use of crops for biofuels.
}

\section{Environmental risk assessment for transgenic crops}

Protection goals and assessment endpoints

The principles of environmental risk assessment for the cultivation of transgenic crops are no different from those for other activities that are considered potentially harmful to the environment (Raybould 2006; Nickson 2008). A risk assessment begins with decisions about what environmental attributes should be protected from harm, and involves two steps: recognition of the general objectives of the law, policy or other instrument that deemed the risk assessment necessary-these objectives are often called "protection goals"; and derivation of explicit, specific targets for protection, which are called "assessment endpoints" (Suter 1990). By their nature, protection goals tend not be amenable to scientific analysis, whereas assessment endpoints must, in principle, be measurable (Newman 1998); for example, assessment endpoints comprising the population size of certain species at particular sites or habitats may be derived from a protection goal of protecting biodiversity.

The next stage of the risk assessment is to determine pathways by which the proposed activity may cause harm. Conceptual models or scenarios that link potential effects of the activity to adverse effects on the assessment endpoints are constructed, and from these models, risk hypotheses for testing are derived (Patton 1998). The risk assessor, in conjunction with decision-makers, must judge whether particular scenarios are sufficiently plausible to warrant further evaluation, because it is possible to produce an infinite number of logical pathways that lead to harm, but most can be ruled out as so unlikely that their further assessment is unnecessary (Wolt et al. 2009).

Risk assessment as hypothesis testing

Risk assessment follows the same deductive logic as basic scientific research: risk is characterised and scientific knowledge is advanced by tests that try to falsify hypotheses, not to find evidence to support ("prove") hypotheses (Popper 1979; Raybould 2006). A risk assessment cannot prove that an activity is safe; however, acceptable risk can be 
demonstrated by sufficient corroboration of risk hypotheses that postulate the absence of harm resulting from that activity. The risk hypotheses derived from the conceptual model are crucial for guiding the evaluation of existing data and the acquisition of new data that may be required to characterize risk. A decision to reject a scenario as too implausible for further evaluation in effect means that existing data corroborate risk hypotheses sufficiently and that additional testing is not required.

In practice, a risk hypothesis postulates that one of the stages in the conceptual model that links an activity to harm is absent; for instance, if a pathway to harm involves a transgenic crop hybridising with a wild plant in a given area, one could test the hypothesis that no hybrids will form there (Raybould and Cooper 2005). Hypotheses postulating the absence of harm need not propose the complete lack of an effect, only that the size or frequency of the effect is below the threshold for harm. In many risk assessments of pesticides, for example, the risk hypotheses are that non-target organisms are not exposed to concentrations of the chemical that produce adverse effects, not that the chemical has no adverse effect at any concentration (e.g., Campbell and Hoy 1996).

The purpose of risk hypotheses is to organise existing information and to evaluate whether additional data are required, and thereby to characterize the likelihood and seriousness of harm. Use of risk hypotheses does not imply that the presence or absence of risk can be determined definitively by the result of a statistical test (Suter 1996). The absence of harm cannot be proven, and thus a decision to permit any activity will always be a judgement that the hypotheses of no harm have been corroborated with sufficient confidence, combined with estimates of the expected benefits of the activity (Raybould 2007). The confidence with which one can judge that an activity poses low risk (is unlikely to result in serious harm) comes from the conservatism of the risk hypotheses and the rigour with which they are tested; thus, if one makes worst-case assumptions about the phenomena necessary for harm to occur, and one cannot detect those phenomena in tests most likely to reveal them, then one may have high confidence that risk is low (Raybould 2006, 2007).
The effectiveness of environmental risk assessment for transgenic crops

Viewing environmental risk assessment of transgenic crops as the formulation and testing of hypotheses that no harm will result from their cultivation is conceptually the same as risk assessments for relatively uncontroversial activities, and is similar to basic scientific research (Raybould 2007). Despite these similarities, risk assessments for transgenic crops are often contentious, and data requirements are unclear, as pointed out recently by Craig et al. (2008): "In the decade since the first authorisations for commercial release of transgenic crops, there has been an enormous increase in the amount of data generated by scientific studies that relates to [risk assessment]. If this trend continues, we run the risk of competent authorities being submerged by excessively large amounts of data that may be of questionable pertinence to verifiable safety questions."

There are many reasons why environmental risk assessments for transgenic crops may appear to be less effective in helping decision-makers than risk assessments for other activities. Undoubtedly, many "non-scientific" concerns-those that cannot be articulated as specific changes to operational assessment endpoints - are manifested as doubts about the thoroughness of environmental risk assessment (Johnson et al. 2007). There is a place for such concerns, but properly they are included in the wider activity of risk analysis, not in risk assessment (Wolt and Peterson 2000; Johnson et al. 2007). Problems with risk assessment also occur because of failures to define harm a priori. Thus instead of testing risk hypothesis of no harm, studies claiming to inform risk assessments have tested hypotheses of no difference between the transgenic crop and a non-transgenic comparator. In effect, these studies sought to objectively discover harm through research, a mistake which has led to exhaustive data collection from field trials, and complex models that require extensive data, but do little or nothing to characterise risk (Raybould 2007).

To summarise, risk assessments for transgenic crops are effective when assessment endpoints are explicit and adverse effects to these endpoints are defined. It is then desirable to target data acquisition to tests of simple hypotheses of no harm. The following section illustrates how assessment endpoints can be 
derived from the protection goals of laws pertaining to the environmental risk assessment of transgenic crops. For brevity and simplicity, the single example of regulation in United States is used, although the same principles apply elsewhere.

\section{Regulatory triggers and assessment endpoints}

Transgenic crops are treated as "regulated articles" by the United States Department of Agriculture (USDA) under the federal Plant Protection Act of 2000 (7 CFR Part 340; NRC 2002; McHughen and Smyth 2008). Regulated articles are regarded as potential plant pests, and the USDA places restrictions on their movement between states, and may impose conditions on field trials to minimise potential harms (for example, by dispersal of pollen or the persistence of volunteer weeds); therefore, the USDA must grant non-regulated status before transgenic crops can be grown commercially without restriction in the United States. If the plant has not been genetically engineered to produce pesticidal compounds, as is likely to be the case for output traits, the petition to the USDA for granting of non-regulated status is the central environmental risk assessment that contributes to regulatory decision-making. If the plant produces pesticides, such as $B t$ proteins, there is an additional regulatory requirement before unrestricted commercialisation: the United States Environmental Protection Agency must register the pesticide under the Federal Insecticide, Fungicide and Rodenticide Act (FIFRA) (McHughen and Smyth 2008). Meeting the protection goals of FIFRA may require a different environmental risk assessment from that needed for the USDA's purposes. In this paper, output trait enzymes are assumed to be not pesticidal.

Non-regulated status is granted if the USDA is satisfied that the transgenic crop is unlikely to become a plant pest under the terms of the FPPA of 1957 (which was incorporated into the Plant Protection Act); however, with completion of a plant pest risk analysis, and prior to granting non-regulated status, the USDA must also consider environmental impacts as defined by the National Environmental Policy Act (NEPA) of 1970 (McHughen and Smyth 2008). The USDA's interpretation of the protection goals of these Acts is not explicit, but may be inferred from statements of the purpose of its various departments; for example, the Animal and Plant Health Inspection Service (APHIS) "safeguards agriculture and natural resources from the risks associated with the entry, establishment, or spread of animal and plant pests and noxious weeds", and thereby "ensures an abundant, high quality, and varied food supply,... and contributes to the preservation of the global environment" (USDA APHIS 2005a). Thus, the protection goals for an environmental risk assessment of plants with output traits may be extremely broad: safeguarding the supply of abundant, high quality and varied food, and preservation of the global environment.

As discussed above, risk assessment requires the derivation of specific assessment endpoints from these general objectives. From precedent established by previous petitions for non-regulated status, and discussions in the literature (e.g., Pimentel et al. 2001; Raybould 2005; Raybould and Cooper 2005), and the likely properties of output trait enzymes, a set of assessment endpoints can be derived for risk assessments of transgenic crops containing output trait enzymes: the abundance of animal species that are not agricultural pests ("wildlife"); the abundance of volunteer crop weeds; the abundance and distribution of feral populations of the crop; and the rate of decomposition of plant material in soil. The derivation of these assessment endpoints, and characterisation of the environmental risks of crops containing output trait enzymes by the testing of conservative risk hypotheses of no harm to these endpoints are described in more detail below in the environmental risk assessment for Event 3272 maize.

\section{Plant characterization}

Regulatory authorities usually require a set of data from the developer that describes the genetic modification and various properties of the transgenic crop (e.g., USDA APHIS 2005b). Production of these data is often regarded as preceding the risk assessment (e.g., Garcia-Alonso et al. 2006) and has two main purposes: to characterize the intended effects of the genetic modification; and to compare the transgenic crop with suitable non-transgenic comparators to establish whether potentially harmful unintended changes resulted from transformation. This concept 
is well-known in food and feed risk assessment, in which various studies test whether the transgenic crop possesses unintended changes that are potentially harmful to human or animal health. If no potentially harmful changes are detected, the risk assessment can concentrate on the intended changes introduced by the genetic modification (Kuiper et al. 2002). If potentially harmful unintended differences are detected, the risks they pose are evaluated along with the intended modifications.

Similar concepts are used for environmental risk assessment of transgenic crops (Horak et al. 2007; Nickson 2008). Various studies characterise the intended effects of the genetic modification, and whether there are unintended changes that are potentially harmful to the environment; collectively, these studies are called "plant characterization" (Horak et al. 2007; Nickson 2008). Similar to food and feed risk assessment, if plant characterization studies show no potentially environmentally harmful unintended changes in the transgenic crop, the risk assessment can concentrate on evaluating whether the intended changes will result in environmental harm; if potentially harmful unintended changes are detected, the risks they pose are assessed together with those of the intended modifications.

If output trait enzymes are produced in a crop species that has not been previously grown in the intended area of cultivation, the method of comparing the crop producing the output trait enzyme with nontransgenic comparators is not available. In these cases, plant characterisation data could be evaluated by weed risk assessment models (e.g., Bennett and Virtue 2004) to assess the likelihood that the new crop producing output trait enzyme will cause environmental harm; in effect the transgenic crop is compared with other species that are not known to be environmentally harmful instead of being compared with non-transgenic genotypes of the crop itself.

Plant characterization and hypothesis testing

The decision to treat plant characterization data as preparatory background information or as hypothesis testing within the risk assessment is a matter of preference (Wolt et al. 2009). Nevertheless, risk assessors should guard against production of data that do not help decision-making (Raybould 2007; Craig et al. 2008). Useful criteria to judge the need for additional data include whether the data permit a more rigorous test of a risk hypothesis than existing data, and whether extra rigour is needed to make a decision (Raybould 2006, 2007). Hence, explicitly testing risk hypotheses may be a useful way to judge the sufficiency of plant characterization data, and this is the approach adopted here.

\section{Molecular characterisation}

In an environmental risk assessment, molecular characterization data can be used to test the hypothesis that the inserted DNA does not trigger production of unintended transgenic proteins, or disrupt plant genes, which may cause the transgenic crop to be harmful. Typically, the complete nucleotide sequence of the DNA insert is determined to confirm that the functional elements of the insert are intact, contiguous and in the intended order. Plant genomic DNA immediately bordering the insert is also sequenced. Analysis of sequence data indicates potential new open reading frames that could produce unintended new proteins and whether the insert has disrupted a known plant gene. Additionally, molecular characterisation includes Southern analysis to determine the copy number of the various functional elements of the inserted DNA and to check that the insert is stably integrated; however, these data tend to be used to evaluate the potential performance of the product not whether it poses an environmental risk.

\section{Plant compositional analysis}

Plant compositional analysis tests the hypothesis of no difference in the concentration of important nutritional components in the transgenic crop and those of a near-isogenic non-transgenic line. The components measured are based on recommendations by the OECD for the crop in question (Table 1). A typical study for the United States compares one or more pairs of transgenic and non-transgenic near isolines in several locations throughout the intended area of cultivation.

The lack of a statistically significant difference in the concentration of the analytes is a strong indicator that transformation has not introduced harmful unintended changes; however, detection of statistically significant differences does not necessarily indicate a 
Table 1 Substances measured in a typical compositional analysis of maize grain

\begin{tabular}{|c|c|c|c|c|c|c|}
\hline Proximates & Minerals & Vitamins & Amino acids & & Fatty acids & $2^{\circ}$ metabolites and antinutrients \\
\hline Protein & Calcium & $\beta$-carotene & Aspartic acid & Methionine & Palmitic acid & Inositol \\
\hline Fat & Copper & Cryptoxanthin & Threonine & Isoleucine & Stearic acid & Phytic acid \\
\hline Ash & Iron & Folic acid & Serine & Leucine & Oleic acid & Raffinose \\
\hline Carbohydrate & Manganese & Thiamine & Glutamic acid & Tyrosine & Linoleic acid & Trypsin inhibitor \\
\hline Acid detergent fibre & Magnesium & Riboflavin & Proline & Phenylalanine & Linolenic acid & Ferulic acid \\
\hline Neutral detergent fibre & Phosphorus & Niacin & Glycine & Histidine & & $p$-Coumaric acid \\
\hline Total dietary fibre & Potassium & Pyridoxine & Alanine & Lysine & & \\
\hline \multirow[t]{3}{*}{ Starch } & Selenium & $\alpha$-tocopherol & Cysteine & Arginine & & \\
\hline & Sodium & & Valine & Tryptophan & & \\
\hline & Zinc & & & & & \\
\hline
\end{tabular}

harmful change. When statistically significant differences are detected, the concentration of the substances involved can be compared with those in databases of crop composition (e.g., Souci et al. 1994; ILSI 2006; USDA 2004). If the concentration in the transgenic crop is within the range for the crop generally, then the difference between the transgenic and non-transgenic lines can be considered biologically insignificant even though the difference is statistically significant.

\section{Feeding studies}

The hypothesis of no harmful unintended changes in the transgenic crop can also be tested by animal feeding studies. The usual test organism is the broiler chicken, which is sensitive to small differences in the nutrient content of its diet because of their rapid growth. For studies of transgenic maize, broilers are fed diets prepared from transgenic and non-transgenic grain, and sometimes an additional diet prepared from commercially available maize grain. Each diet treatment typically comprises at least 150 male and 150 female birds, with the sexes kept separately in pens of between 25 and 30 birds. The main measurement endpoint in the study is body weight measured at 21, 35 and 42 or 49 days (e.g., Brake et al. 2003; 2005).

\section{Phenotypic characterization}

During development, transgenic crops undergo extensive phenotypic characterization in agronomic trials.
Agronomic trials for regulatory purposes in the United States are carried out throughout the area where the crop will be cultivated, and usually are done over at least 2 years. Most of this work is done to investigate the agronomic performance of the crop, and its efficacy if relevant. Nevertheless, many of the data are useful for environmental risk assessment as they can be used to test the hypothesis that the weediness and invasiveness potential of the transgenic crop is no greater than its non-transgenic counterpart: if there are no significant differences in characters associated with survival, growth and reproduction, then it is likely that the weediness and invasive potential of the transgenic crop is no greater than non-transgenic crop. A typical set of traits used to characterize maize phenotypes in field trials is shown in Table 2.

\section{Developmental expression study}

Developmental expression studies measure the concentration of the transgenic proteins of interest in plants grown according to standard local agronomic practice. Concentrations are measured by enzymelinked immunosorbent assay (ELISA) (Tijssen 1985) at several developmental stages and in several tissues-usually, leaves, roots, pollen, seeds and whole plants; nectar and flowers may also be assayed in some cases. In an environmental risk assessment, the developmental expression study provides information to estimate exposure of wildlife to the transgenic proteins. 
Table 2 Traits typically measured in the agronomic trials used for phenotypic characterization of transgenic maize

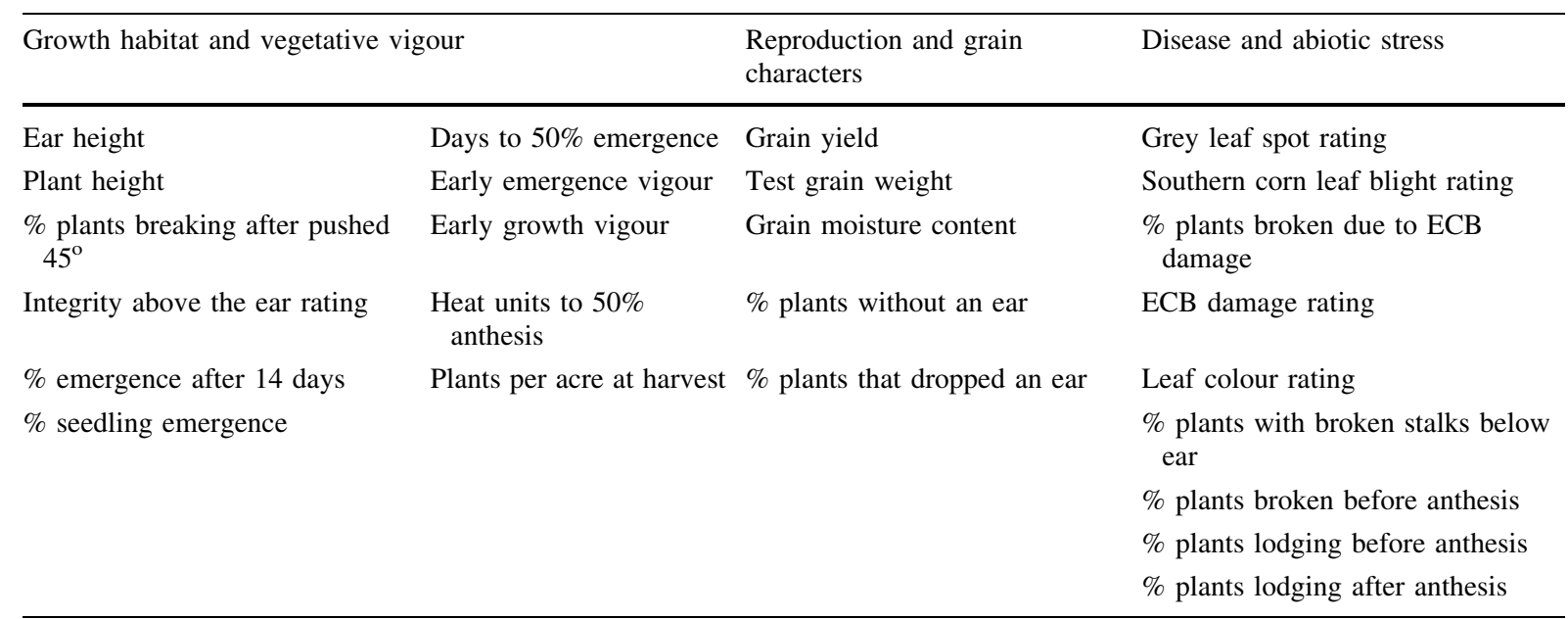

\section{Summary environmental risk assessment for cultivation of Event 3272 maize in the United States}

The preceding sections have described environmental risk assessment principles and data requirements that may be applied to the risk assessment of any transgenic crop. The following sections illustrate how the specific risks posed by expression of output trait enzymes may be assessed using the example of AMY797E in Event 3272 maize. While the intended use of output trait enzymes will differ among transgenic crops, the assessment endpoints, conceptual models, risk hypotheses, hypothesis testing and risk characterisation for Event 3272 maize are relevant to any crop in which the presence of additional enzymes is the useful phenotype, and in which the additional enzymes are not intended to manipulate plant metabolism or development, or to be toxic to organisms that may be exposed to the crop.

Effects on wildlife

\section{Assessment endpoints and risk hypotheses}

The protection goals of the environmental risk assessment for cultivation of transgenic crops containing output trait enzymes were identified above as safeguarding an abundant, high quality and varied food and preservation of the global environment. A supply of abundant and high quality food is dependent on organisms such as pollinators and biological control organisms, and the preservation of the global environment could include maintaining the abundance of animals of particular conservation interest, or indeed any animal that is not harmful to the environment (plants are considered below). Thus, a highly conservative assessment endpoint for this risk assessment is the abundance of animals that are not agricultural pests or livestock-risks to livestock are usually considered in food and feed risk assessments. Non-pest species are usually called non-target organisms in risk assessments for pesticidal crops, but as there are no target species of crops containing output trait enzymes, "wildlife" is a convenient alternative term. The assessment endpoint is conservative because not all non-agricultural pest species may be valuable, so reduced abundance would not be harmful; however, it is simpler to consider all nonpest species in the first instance.

Risks to wildlife from cultivation of Event 3272 maize can be characterised by testing 3 risk hypotheses:

1. There are no ecotoxicologically significant differences between the Event 3272 maize and a suitable non-transgenic comparator, apart from the intended production of AMY797E

2. There is no exposure of wildlife to AMY797E

3. If there is exposure to the AMY797E, it is below amounts that have adverse effects 
If the first hypothesis is corroborated sufficiently, the risk assessment can concentrate on the exposure to AMY797E. Testing of the second hypothesis with a developmental expression study enables certain pathways of exposure to be eliminated; for example, if AMY797E is not detectable in pollen, then organisms that ingest pollen, but no other tissue of maize, would be at minimal risk from dietary toxicity of AMY797E, regardless of how toxic the protein may be. Tests of the third hypothesis evaluate the likelihood that AMY797E is toxic to wildlife at exposures via cultivation of Event 3272 maize.

The hypothesis of no ecotoxicologically significant differences between Event 3272 maize and nontransgenic maize was extensively corroborated. Molecular analysis of Event 3272 maize showed that it contains a single T-DNA insert, with the functional sequences intact and in the expected order and stably inherited; and the insertion of the T-DNA did not appear to have disrupted endogenous Zea mays genes, or to have created new open reading frames. Compositional analysis was conducted on grain from several Event 3272 maize and near-isogenic, nontransgenic hybrids grown in randomized trials in the US Corn Belt at six sites in 2003 and six sites in 2004. Some small but statistically significant differences were seen in some of the comparisons in some of the components in the proximate, fibre, mineral, vitamin, amino acid, and secondary metabolite analyses; however, the values for all components were in the range of data published in the literature. Finally, the body weight of broiler chickens raised on diets containing Event 3272 grain were not significantly different from the weights of chickens raised on diets containing grain from a near-isogenic line, nor from chickens raised on diets prepared from commercially available maize grain.

\section{Exposure of wildlife to AMY797E}

The amy $797 E$ gene in Event 3272 maize is expressed from the $Z$. mays gamma-zein promoter (Das et al. 1991) which directs expression of AMY797E to the endosperm tissue of the maize kernel. The developmental expression study showed, as expected, that AMY797E was almost completely confined to the kernels: the mean concentration of AMY797E in kernels was at least 625 times the highest concentration in any other tissue. The mean concentration of
AMY797E in kernels was consistent among developmental stages, and there was about a 3-fold difference between the highest and lowest concentrations of AMY797E among all kernel samples (701 to $2,144 \mu \mathrm{g} / \mathrm{g}$ fresh weight).

Maize rarely establishes outside cultivation (OECD 2003) and there are no sexually compatible wild relatives of maize in the United States (US EPA 2001); therefore, exposure of wildlife to AMY797E is likely to be limited to animals that eat maize grain in or around agricultural fields. Many insects eat kernels in the ears of maize or eat planted seeds; however, all these species are regarded as pests (Steffey et al. 1999). Rodents feed on germinating maize seeds and larger mammals, including white-tailed deer (Odocoilus virginianus) and raccoons (Procyon lotor), cause injury to ripening ears. Birds such as crows (Corvus brachyrhynchos), grackles (Quiscalus quiscula) and sandhill cranes (Grus canadensis) uproot sprouting maize to feed on the germinating kernels (Blackwell et al. 2001; Sterner et al. 2003). Blackbirds are also common in maize stubble where they forage for spilled maize kernels and weed seeds (Linz et al. 2003). While rodents and birds are serious pests of maize (Steffey et al. 1999), for the purposes of this risk assessment they are considered to be wildlife as they may feed on spilled seed without damaging the crop, and unintended reductions in their population size due to toxicity of AMY797E may be regarded as unacceptable.

\section{Potential adverse effects of dietary exposure to AMY797E}

For non-pesticidal proteins, such as AMY797E, the likely effects of exposure are usually assessed from a weight of evidence, rather than a series of laboratory ecotoxicology studies as is usual for pesticidal proteins (e.g., Raybould et al. 2007). Data on the protein's mode-of-action, its similarity to known toxins, and exposure of wildlife to similar proteins are all useful for testing hypotheses of no harmful effect of exposure via the crop, and may characterise risk sufficiently to make hazard testing of the protein unnecessary. In general, however, the weight of evidence approach is considered insufficient for human and livestock health risk assessments, and therefore toxicology studies of the protein are undertaken. These studies can be used to further 
corroborate hypotheses of no harm to wildlife, even though they may not be absolutely necessary for a rigorous environmental risk assessment.

Alpha-amylases are ubiquitous, occurring in all three Domains of life (Bacteria, Archaea and Eukaryota, including humans) (Horii et al. 1987; Pujadas and Palau 2001). Alpha-amylases occur widely in plants (Huang et al. 1992), and they are common in crops, including maize, in which starch is a main storage product (van der Maarel et al. 2002); and amylases are widespread in soil microbes, including some that are heat-tolerant (Mellouli et al. 2005). It is likely, therefore, that species exposed to AMY797E via Event 3272 maize have prior exposure to alpha-amylases. No harmful effects of such exposure are known.

The hypothesis that AMY797E has no significant amino acid sequence similarity to know toxins was tested using BLASTP analysis (Altschul et al. 1994). The amino acid sequence of the AMY797E precursor (i.e., AMY797E and the sequences to target it to the endoplasmic reticulum) was shuffled randomly and five random sequences were compared with proteins in National Center for Biotechnology Information (NCBI) Entrez Protein Database. The comparison was then performed with the AMY797E precursor sequence, and proteins with a higher degree of sequence similarity to AMY797E than to any of the random sequences were identified for further analysis. Many of these proteins were alpha-amylases, and none was a known toxin.

The acute toxicity of AMY797E to mice was tested using standard methods (US EPA 1998). The test substance was AMY797E-0104, a lyophilized preparation of AMY797E from Event 3272 grain. AMY797E-0104 contained about 42\% AMY797E w/ w. Mice were exposed to a single oral dose of 3,600 mg AMY797E-0104/kg body weight, equivalent to $1,511 \mathrm{mg}$ AMY797E/kg body weight. There were no observed adverse effects of exposure to AMY797E-0104.

\section{Risk characterization}

Cultivation of Event 3272 maize is unlikely to harm wildlife. First, extensive plant characterization detected no harmful unintended effects of transformation. Secondly, a weight of evidence from bioinformatics and prior exposure to alpha-amylases indicates that AMY797E is unlikely to be a toxin. Finally, an acute toxicity study in mice indicated no adverse effects of a single oral dose of $1,511 \mathrm{mg}$ AMY797E $/ \mathrm{kg}$ body weight. To estimate the margin of exposure of this dose, the daily dietary dose (DDD) of AMY797E for rodents can be calculated using the methods of Crocker et al. (2002). The formula for daily dietary dose is

$\mathrm{DDD}=\frac{\mathrm{FIR}}{\mathrm{bw}} \times \mathrm{C}$

where FIR $=$ food intake rate, bw = body weight and $\mathrm{C}=$ concentration of AMY797E in food.

Crocker et al. (2002) estimated the ratio of food intake rate and body weight (FIR/bw) for several rodent species. The values for the harvest mouse (Micromys minutus) and the wood mouse (Apodemus sylvaticus) consuming cereal seeds are 0.33 and 0.28 , respectively. The highest concentration of AMY797E recorded in kernels of Event 3272 maize is 2,144 $\mu \mathrm{g}$ AMY797E/g fresh weight; therefore, a worst-case DDD for rodents eating a diet comprising $100 \%$ kernels of Event 3272 maize is approximately $708 \mathrm{mg}$ AMY797E/kg body weight. The dose in the mouse study therefore represents about $2.1 \times$ the worst-case DDD based on a diet entirely comprising Event 3272 grain with the highest measured amount of AMY797E.

No study of the acute effects of AMY797E on birds has been carried out; however, a long term feeding study (49 days), in which broiler chickens were fed diets containing between 52 and $65 \%$ Event 3272 maize grain revealed no harmful effects (see above). Thus, the risks to wildlife from exposure to AMY797E via cultivation of Event 3272 maize are minimal.

Assessment of weediness and invasiveness potential

\section{Assessment endpoints and risk hypotheses}

The potential harm from increased weediness potential relates to the protection goal of safeguarding the supply of abundant, high quality and varied food. Increased abundance of volunteer weeds resulting from the cultivation of transgenic crops producing output trait enzymes could reduce the abundance of food because of decreased yields. While the ultimate 
assessment endpoint is crop yield, it is simpler to define the assessment endpoint as the abundance of volunteers. This endpoint is conservative, because if no change in abundance is predicted, then yield and quality are protected; however, the converse does not apply: changes in abundance will not necessarily lead to reduced yield.

Possible harm from increased invasiveness potential is also relevant to the protection goal of preserving the global environment. Invasive species have serious adverse environmental effects, including displacement of native plant species and animal species that rely on them, reduced water supply, increased frequency of fires, changed nutrient cycles and loss of yield in natural pastures (Pimentel et al. 2001). These adverse effects could be used to derive assessment endpoints, such as population sizes of native plant species, or the frequency of fires in a given area, but again it is simpler and more conservative to use the abundance of feral populations of crops as the assessment endpoint for risks from increased invasiveness (Raybould and Cooper 2005).

Maize is a highly domesticated crop that has lost the ability to persist in the wild: it has no primary dormancy, requires disturbed ground to germinate and has extremely limited seed dispersal because kernels are retained on the cob. Maize can volunteer in subsequent crops, particularly soybeans (Beckett and Stoller 1988); however, it is easily controlled with selective herbicides, and any plants that escape control usually do not produce viable progeny (OECD 2003). Maize plants are not invasive of natural habitats (Gould 1968), and although plants can establish outside cultivation from seed spilled during transport, feral maize is unable to form selfsustaining populations (OECD 2003). Given the low weediness and invasiveness potential of maize, a very conservative risk hypothesis is that the weediness and invasiveness potential of Event 3272 maize is no greater than that of non-transgenic maize.

\section{Risk hypothesis testing}

The hypothesis that the weediness and invasiveness potential of Event 3272 maize is no greater than that of non-transgenic maize was tested by phenotypic characterization of Event 3272 maize and nearisogenic non-transgenic maize genotypes. The maize was grown in agronomic trials at 25 sites throughout the US Corn Belt in 2003 and 2004. Several traits related to growth habit, vegetative vigour, reproduction, yield and grain characteristics, disease and abiotic stress that may be associated with weediness or invasiveness potential were measured (Table 2). In growth habit, Event 3272 had less favourable late season intactness and push test scores than the control maize genotypes; however, Event 3272 maize had better scores than the control maize genotypes for percent broken stalks. Overall, characteristics evaluating growth habit did not differ between Event 3272 maize and the near-isogenic, non-transgenic maize. In vegetative vigour, Event 3272 maize was comparable to the control maize in early emergence vigour, early growth rating and ear height. Some Event 3272 maize hybrids were shorter than the control maize hybrids, but while this difference was statistically significant, it was small and a reduction in height is unlikely to be associated with increased weediness. Event 3272 maize had a higher percentage of barren plants than the control maize hybrids at some locations, but potentially higher barrenness of Event 3272 maize under some environmental conditions would not increase the weediness potential. Event 3272 maize was comparable to the near-isogenic, non-transgenic maize in abiotic stress assessments, which included measurements of early and late root lodging and percentage of snapped plants.

In addition to data from agronomic trials, the risk hypothesis was tested in laboratory dormancy trials. Dormancy is important means by which weeds avoid control measures (Dyer 1995) and therefore an increase in dormancy is an indicator of increased weediness potential. A laboratory experiment was conducted using methods recommended by the Association of Official Seed Analysis (AOSA 1998) to determine if primary dormancy of Event 3272 seed differed from that of seed of a non-transgenic nearisogenic control line under optimum germination conditions $\left(25^{\circ} \mathrm{C}\right.$ for 7 days), and under normal spring germination conditions in the field $\left(10^{\circ} \mathrm{C}\right.$ for 4 days, $25^{\circ} \mathrm{C}$ for 3 days). In addition, seed viability after 7 days at $5^{\circ} \mathrm{C}$ was measured to test for differences in overwintering ability (secondary dormancy).

No statistically significant differences in germination were observed between Event 3272 seed and the non-transgenic near-isogenic control seed under optimum or field conditions. The proportion of dead 
seed at $5^{\circ} \mathrm{C}$ was significantly greater in the Event 3272 seed sample.

\section{Risk characterization}

Phenotypic characterization and dormancy assays corroborated the hypothesis of no increased weediness and invasiveness potential of Event 3272 maize. Thus Event 3272 maize is no more likely than nontransgenic maize to volunteer or to form feral populations and thereby harm crop yield or the abundance of wildlife. The risk of volunteer Event 3272 maize affecting the quality of subsequent crops is low because Event 3272 maize will be grown as a speciality crop and managed for identity preservation in the same manner as other high-value products such as white corn and waxy corn (Elbehri 2007); identity preservation will also minimise gene flow from Event 3272 maize to other maize crops. The cultivation of Event 3272 maize therefore poses minimal risk to the provision of abundant, high-quality food or to preservation of the global environment through its potential for weediness and invasiveness.

Assessment of effects on soil

Transgenic crops containing output trait enzymes, especially those to be used as biofuels, are likely to contain modified forms or increased amounts of enzymes that metabolise plant structural carbohydrates. When material from such crops enters the soil, there is the possibility that enzyme activity in the soil will be altered; the likelihood of harm arising from altered soil enzyme activity should therefore be assessed in the environmental risk assessment. Recently, Wolt and Karaman (2007) pointed out that cultivation of Event 3272 maize may increase the amount of alpha-amylase in soil by up to 10 times the background concentration because AMY797E will enter soil as the result of Event 3272 seed spillage during harvest. While this increased concentration is unlikely to have adverse effects through toxicity to soil organisms (see above), Wolt and Karaman postulated that there may be effects of AMY797E on soil quality.

\section{Assessment endpoints and risk hypotheses}

Schloter et al. (2003) defined soil quality as, "the continued capacity of soil to function as a vital living system, within ecosystem and land use boundaries, sustain biological productivity, to promote the quality of air and water environments, and to maintain plant, animal and human health". Thus, protection of soil quality is essential to meet the protection goal of safeguarding an abundant food supply.

Soil quality is difficult to operationalize fully because it is the product of interactions between multiple attributes (Nortcliff 2002; Gil-Sotres et al. 2005), and therefore is not as a clear an assessment endpoint as, say, the abundance of particular species of wildlife. One solution is to create an index of attributes (Bohanec et al. 2007), which can serve as a composite assessment endpoint. A more common approach is to use particular soil attributes that are the most valued, or are the most likely to be affected by the product or process being assessed; these attributes are assessment endpoints in themselves, but can also be regarded as surrogates for soil quality. In the case of soil risk assessments for agricultural pesticides, the assessment endpoint is typically some index of soil function measured as the rate of respiration, the rate of nitrogen transformation and the rate of decomposition of organic matter (EPPO 2003; Knacker et al. 2003; Römbke 2006), although these endpoints are not independent (Mary et al. 1996).

Some authors use measurements of amylase activity as a test for harm to soil (Ismail et al. 1998; Gundi et al. 2007), because amylase is one of a suite of enzymes that degrade organic matter (Gil-Sotres et al. 2005). On this basis, one could formulate a risk hypothesis for Event 3272 maize of no reduction in amylase activity, which is strongly corroborated by Wolt and Karaman's estimate that cultivation of Event 3272 maize may increase soil amylase activity by an order of magnitude. This risk hypothesis is too simple for Event 3272 maize, because it is not clear that an increase in the rate of plant decomposition above the background is always beneficial. Degradation of maize residues is a valuable source of soil nutrients (Recous et al. 1995; Vazquez et al. 2003), and some studies have shown that faster decomposition can lead to lower incorporation of carbon and nitrogen in the soil (Bernal et al. 1998; Hadas et al. 2004). To account for the possibility of harm from increased, as well as decreased, degradation rates, a conservative risk hypothesis is that addition of AMY797E to the soil will not significantly change the rate of decomposition of maize residues remaining after harvest. 


\section{Risk hypothesis testing}

A weight of evidence corroborates the hypothesis of no significant change in the rate of decomposition of maize residues due to addition of AMY797E to soil. First, many authors do not consider amylase to be a good indicator of soil quality. There are models of enzymatic degradation of plant residues that do not include amylase (e.g., Sinsabaugh et al. 1994), and some authors specifically recommend not using amylase due to its unimportance compared with other enzymes (Kang et al. 2005).

Secondly, starch decomposition in soil is rapid compared with other structural components of plant tissues (Fioretto et al. 2001; Kögel-Knaber 2002; Waldrop and Firestone 2004), indicating that degradation of plant material is not usually limited by availability of soil amylases. This is probably because micro-organisms that produce amylase are stimulated to grow by addition of plant material and organic matter: soil amylase activity has been shown to follow seasonal changes in leaf litter (Kshattriya et al. 1992; Joshi et al. 1993), and to increase after the addition of crop residues (Perucci et al. 1984) or other organic material (Perucci 1992), and after fire (Acea and Carballas 1996). Increases in amylase activity of 10 -fold or greater have been observed. Finally, maize residues contain minimal amounts of starch. Stover contains about $60 \%$ carbohydrate, of which the principal components are cellulose and hemicellulose, the latter comprising mainly xylan, with small amounts of arabinan, mannan and galactan. Most of the non-carbohydrate component is lignin (Sheenan et al. 2004).

\section{Risk characterization}

A 10-fold increase in the concentration of soil alphaamylases following cultivation of Event 3272 maize is unlikely to be harmful. The main process potentially affected is the degradation of maize residues. Maize residues contain little starch, the substrate of AMY797E, and addition of plant material to soil rapidly induces alpha-amylase activity; therefore, the rate of degradation of maize residues is unlikely to be altered by the presence of AMY797E in soil because the rate of degradation is rarely, if ever, limited by amylase activity.

\section{Conclusion}

A weight of evidence indicates that cultivation of Event 3272 maize expressing AMY797E for improved bioethanol production poses low risk to the environment: it is unlikely to reduce the abundance of wildlife, reduce crop yield or change the rate of degradation of plant material in soil. The risk assessment for Event 3272 maize shows that the environmental risks from cultivating crops producing output trait enzymes can be rigorously evaluated by testing conservative risk hypotheses using data from many sources, including evaluations of agronomic performance nutritional quality of the crop made during product development, and information from the scientific literature on the mode-of-action, taxonomic distribution and environmental fate of the enzyme. In many cases it is likely that the environmental risks from cultivation of transgenic plants producing output trait enzymes can be assessed with sufficient confidence without most, or indeed any, of the specific ecotoxicological studies that are required to assess the environmental risks from pesticidal transgenic crops. The effective use of existing data means that regulatory decision-making, to which an environmental risk assessment provides essential information, is not unnecessarily complicated by evaluation of large amounts of data that provide a negligible improvement in the characterization of risk (Romeis et al 2009), and that may delay environmental benefits offered by transgenic crops containing output trait enzymes.

Open Access This article is distributed under the terms of the Creative Commons Attribution Noncommercial License which permits any noncommercial use, distribution, and reproduction in any medium, provided the original author(s) and source are credited.

\section{References}

Acea M, Carballas T (1996) Changes in physiological groups of organisms in soil following wildfire. FEMS Microbiol Ecol 20:33-39

Altschul SF, Madden TL, Schäffer AA, Zhang J, Zhang Z, Miller W, Lipman DJ (1994) Gapped BLAST and PSIBLAST: a new generation of protein database search programs. Nucleic Acids Res 25:3389-3402

AOSA (Association of Official Seed Analysis) (1998) Rules for testing seeds. Association of Official Seed Analysis, Lincoln 
Beckett TH, Stoller EW (1988) Volunteer corn (Zea mays) interference in soybeans (Glycine max). Weed Sci 36:159-166

Bennett SJ, Virtue JG (2004) Salinity mitigation versus weed risks-can conflicts of interest in introducing new plants be resolved? Aust J Exp Agric 44:1141-1156

Bernal MP, Sánchez-Monedero MA, Parades C, Roig A (1998) Carbon mineralization from organic wastes at different composting stages during their incubation with soil. Agricult Ecosyst Environ 69:175-189

Blackwell BF, Helon DA, Dolbeer RA (2001) Repelling sandhill cranes from corn: whole-kernel experiments with captive birds. Crop Prot 20:65-68

Bohanec M, Cortet J, Griffiths B, Žnidaršič M, Debeljak M, Caul S, Thompson J, Krogh P (2007) A qualitative multiattribute model for assessing the impact of cropping systems on soil quality. Pedobiologia 51:239-250

Bouis HE, Chassy BM, Ochanda JO (2003) Genetically modified food crops and their contribution to human nutrition and food quality. Trends Food Sci Tech 14:191-209

Brake J, Faust M, Stein J (2003) Evaluation of transgenic event Bt11 hybrid corn in broiler chickens. Poultry Sci 82:551559

Brake J, Faust M, Stein J (2005) Evaluation of transgenic hybrid corn (VIP3A) in broiler chickens. Poultry Sci 84:503-512

Campbell PJ, Hoy SP (1996) ED points and NOELs: how they are used by UK pesticide regulators. Ecotoxicology 5:139-144

Chapotin SM, Wolt JD (2007) Genetically modified crops for the bioeconomy: meeting public and regulatory expectations. Transgenic Res 16:675-688

Craig W, Tepfer M, Degrassi G, Ripandelli D (2008) An overview of general features of risk assessments of genetically modified crops. Euphytica 164:853-880

Crocker D, Hart A, Gurney J, McCoy C (2002) Project PN0908: methods for estimating daily food intake of wild birds and mammals. Central Science Laboratory, York, UK. Available at http://www.detergents.gov.uk/uploaded files/Web_Assets/PSD/Research_PN0908.pdf

Das O, Ward K, Ray S, Messing J (1991) Sequence variation between alleles reveals two types of copy correction at the 27-kDa zein locus of maize. Genomics 11:849-856

Dyer WE (1995) Exploiting weed seed dormancy and germination requirements through agronomic practices. Weed Sci 43:498-503

Elbehri A (2007) The changing face of the US grain system: differentiation and identify preservation trends. United States economic research service report \# 35. Available at http://ddr.nal.usda.gov/dspace/bitstream/10113/19379/1/ CAT30979536.pdf

EPPO (European, Mediterranean Plant Protection Organisation) (2003) Environmental risk assessment scheme for plant protection products. Chapter 8. Soil organisms and functions. Bull OEPP 33:195-209

Fioretto A, Papa S, Sorrentino G, Fuggi A (2001) Decomposition of Cistus incanus leaf litter in a Mediterranean maquis ecosystem: mass loss, microbial enzyme activities and nutrient changes. Soil Biol Biochem 33:311321
Flachowsky G, Chesson A, Aulrich K (2005) Animal nutrition with feeds from genetically modified plants. Arch Anim Nutr 59:1-40

Garcia-Alonso M, Jacobs E, Raybould A, Nickson TE, Sowig P, Willekens H, van der Kouwe P, Layton R, Amijee F, Fuentes A, Tencalla F (2006) A tiered system for assessing the risk of genetically modified plants to nontarget organisms. Environ Biosafety Res 5:57-65

Gil-Sotres F, Trasar-Cepeda C, Leirós MC, Seoane S (2005) Different approaches to evaluating soil quality using biochemical properties. Soil Biol Biochem 37:877-887

Gould FW (1968) Grass systematics. McGraw Hill, New York

Gundi VAKB, Viswanath B, Chandra MS, Kumar VN, Reddy BR (2007) Activities of cellulase and amylase in soils as influenced by pesticide interactions. Ecotoxicol Environ Saf 68:278-285

Hadas A, Kautsky L, Goek M, Kara EE (2004) Rates of decomposition of plant residues and available nitrogen in soil, related to residue composition through simulation of carbon and nitrogen turnover. Soil Biol Biochem 36:255266

Horak MJ, Rosenbaum EW, Woodrum CL, Martens AB, Mery RF, Cothren JT, Burns JA, Nickson TE, Pester TA, Jiang C, Hart JL, Sammons B (2007) Characterization of roundup ready flex cotton, MON88913, for use in ecological risk assessment: evaluation of seed germination, vegetative and reproductive growth, and ecological interactions. Crop Sci 47:268-277

Horii A, Emi M, Tomita N, Nishide T, Ogawa M, Mori T, Matsubara K (1987) Primary structure of human pancreatic alpha-amylase gene: its comparison with human salivary alpha-amylase gene. Gene 60:57-60

Huang N, Stebbins GL, Rodriguez RL (1992) Classification and evolution of alpha-amylase genes in plants. Proc Natl Acad Sci USA 89:7526-7530

ILSI (International Life Sciences Institute) (2006) International life sciences institute crop composition database version 2.0. available at http://www.cropcomposition.org

Ismail BS, Yapp KF, Omar O (1998) Effects of metsulfuronmethyl on amylase, urease and protease activities in two soils. Aust J Soil Res 36:449-456

Johnson KL, Raybould AF, Hudson MD, Poppy GM (2007) How does scientific risk assessment of GM crops fit within the wider risk analysis? Trends Plant Sci 12:1-5

Joshi SR, Sharma GD, Mishra RR (1993) Microbial enzyme activities related to litter decomposition near a highway in a sub-tropical forest of north east India. Soil Biol Biochem 12:1763-1770

Kang GS, Beri V, Sidhu BS, Rupela OP (2005) A new index to assess soil quality and sustainability of wheat-based cropping systems. Biol Fertil Soils 41:389-398

Knacker T, Förster B, Römbke J, Frampton GK (2003) Assessing effects of plant protection products on organic matter in arable fields-litter decomposition test systems. Soil Biol Biochem 35:1269-1287

Kögel-Knaber I (2002) The macromolecular organic composition of plant and microbial residues as inputs to soil organic matter. Soil Biol Biochem 34:139-162

Kshattriya S, Sharma GD, Mishra RR (1992) Enzyme activities related to litter decomposition in forests of different age 
and latitude in north east India. Soil Biol Biochem 11:265-270

Kuiper HA, Kleter GA, Noteborn HPJM, Kok EJ (2002) Substantial equivalence-an appropriate paradigm for the safety assessment of genetically modified foods? Toxicology 181-182:427-431

Linz GM, Knutsen GA, Homan HJ, Bleier WJ (2003) Baiting blackbirds (Icteridae) in stubble grain fields during spring migration in South Dakota. Crop Prot 22:261-264

Lynd LR, Wyman CE, Gerngross TU (1999) Bioprocess engineering and biobased industrial products. Biotech Prog 15:777-793

Mary B, Recous S, Darwis D, Robin D (1996) Interactions between decomposition of plant residues and nitrogen cycling in soil. Plant Soil 181:71-82

McHughen A, Smyth S (2008) US regulatory system for genetically modified [genetically modified organism (GMO), rDNA or transgenic] crop cultivars. Plant Biotechnol J 6:2-12

Mellouli L, Ghorbel R, Virolle MJ, Bejar S (2005) Alphaamylase gene of thermophilic Streptomyces sp. TO1: nucleotide sequence, transcriptional and amino acid sequence analysis. FEMS Microbiol Lett 160:17-23

Napier JA (2007) The production of unusual fatty acids in transgenic plants. Ann Rev Plant Biol 58:295-319

Newman NC (1998) Fundamentals of ecotoxicology. Ann Arbor Press, Chelsea

Nickson TE (2008) Planning environmental risk assessment for genetically modified crops: problem formulation for stress-tolerant crops. Plant Physiol 147:494-502

Nortcliff S (2002) Standardisation of soil quality attributes. Agricult Ecosyst Environ 88:161-168

NRC (National Research Council) (2002) Environmental effects of transgenic plants: the scope and adequacy of regulation. National Academy Press, Washington

OECD (Organisation for Economic Co-operation and Development) (2003) Consensus document on the biology of Zea mays subsp. mays. Series on harmonisation of regulatory oversight in biotechnology, No. 27. Available at http://www. olis.oecd.org/olis/2003doc.nsf/LinkTo/NT0000426E/\$FILE/ JT00147699.PDF

Oraby H, Venkatesh B, Dale B, Ahmad R, Ransom C, Oehmke J, Sticklen M (2007) Enhanced conversion of plant biomass into glucose using transgenic rice-produced endoglucanase for cellulosic ethanol. Transgenic Res 16:739-749

Patton DE (1998) Environmental risk assessment: tasks and obligations. Hum Ecol Risk Assess 4:657-670

Perucci P (1992) Enzyme activity and microbial biomass in a field soil amended with municipal refuse. Biology Fertil Soils 14:54-60

Perucci P, Scarponi L, Businelli M (1984) Enzyme activities in a clay-loam soil amended with various crop residues. Plant Soil 81:345-351

Pimentel D, McNair S, Janecka J, Wightman J, Simmonds C, O'Connell C, Wong E, Russel L, Zern J, Aquino T, Tsomondo T (2001) Economic and environmental threats of alien plant, animal, and microbe invasions. Agric Ecosyst Environ 84:1-20

Popper KR (1979) Objective knowledge: an evolutionary approach. Oxford University Press, Oxford, UK
Privalle L (2002) Phosphomannose isomerase, a novel plant selection system: potential allergenicity assessment. Ann NY Acad Sci 964:129-138

Pujadas G, Palau J (2001) Evolution of $\alpha$-amylases: architectural features and key residues in the stabilization of the $(\beta / \alpha)_{8}$ scaffold. Mol Biol Evol 18:38-54

Ragauskas AJ, Williams CK, Davison BH, Britovsek G, Cairney J, Eckert CA, Frederick WJ Jr, Hallett JP, Leak DJ, Liotta CL, Mielenz JR, Murphy R, Templer R, Tschaplinski $\mathrm{T}$ (2006) The path forward for biofuels and biomaterials. Science 311:484-489

Raybould A (2005) Assessing the environmental risks of transgenic volunteer weeds. In: Gressel J (ed) Crop ferality and volunteerism. CRC Press, Boca Raton, pp 389-401

Raybould A (2006) Problem formulation and hypothesis testing for environmental risk assessments of genetically modified crops. Environ Biosafety Res 5:119-125

Raybould A (2007) Ecological versus ecotoxicological methods for assessing the environmental risks of transgenic crops. Plant Sci 173:589-602

Raybould A, Cooper JI (2005) Tiered tests to assess the environmental risk of fitness changes in hybrids between transgenic crops and wild relatives: the example of virus resistant Brassica napus. Environ Biosafety Res 4:127-140

Raybould A, Stacey D, Vlachos D, Graser G, Li X, Joseph R (2007) Non-target organism risk assessment of MIR604 maize expressing mCry $3 \mathrm{~A}$ for control of corn rootworm. J Appl Entomol 131:391-399

Recous S, Robin D, Darwis D, Mary B (1995) Soil inorganic N availability: effect on maize residue decomposition. Soil Biol Biochem 27:1529-1538

Reed J, Privalle L, Luann Powell M, Meghji M, Dawson J, Dunder E, Suttie J, Wenck A, Launis K, Kramer C, Chang Y-F, Hansen G, Wright M (2001) Phosphomannose isomerase: an efficient selectable marker for plant transformation. In vitro cellular and developmental biology. Plant 37:127-132

Römbke J (2006) Tools and techniques for the assessment of ecotoxicological impacts of contaminants in the terrestrial environment. Hum Ecol Risk Assess 12:84-101

Romeis J, Lawo NC, Raybould A (2009) Making effective use of existing data for case-by-case risk assessments of genetically engineered crops. J Appl Entomol. doi: 10.1111/j.1439-0418.2009.01423.x

Schloter M, Dilly O, Munch JC (2003) Indicators of soil quality. Agric Ecosyst Environ 98:255-262

Sheenan J, Aden A, Paustian K, Killian K, Brenner J, Walsh M, Nelson R (2004) Energy and environmental aspects of using corn stover for fuel ethanol. J Ind Ecol 7:117-146

Singh V, Batie CJ, Aux GW, Rausch KD, Miller C (2006) Drygrind processing of corn with endogenous liquefaction enzymes. Cereal Chem 83:317-320

Sinsabaugh RL, Moorhead DL, Linkins AE (1994) The enzymic basis of plant litter decomposition: emergence of an ecological process. Appl Soil Ecol 1:97-111

Souci SW, Fachmann W, Kraut H (1994) Food composition and nutrition tables, 5th edn. CRC Press, Stuttgart

Steffey KL, Rice ME, All J, Andow DA, Gray ME, van Duy JW (1999) Handbook of corn insects. Entomological Society of America, Lanham 
Sterner RT, Petersen BE, Gaddis SE, Tope KL, Poss PJ (2003) Impacts of small mammals and birds on low-tillage, dryland crops. Crop Prot 22:595-602

Sticklen MB (2006) Plant genetic engineering to improve biomass characteristics for biofuels. Curr Opinion Biotech $17: 315-319$

Sticklen MB (2008) Plant genetic engineering for biofuel production: towards affordable cellulosic ethanol. Nature Rev Genet 9:433-443

Suter GW (1990) Endpoints for ecological risk assessments. Environ Manage 14:9-23

Suter GW (1996) Abuse of hypothesis testing statistics in ecological risk assessment. Hum Ecol Risk Assess 2:331-347

Tijssen P (1985) Processing of data and reporting of results of enzyme immunoassays. Practice and theory of enzyme immunoassays. Lab Tech Biochem Mol Biol 15:385-421

US EPA (United States Environmental Protection Agency) (1998) Heath effects test guidelines. OPPTS 870.1100. Acute oral toxicity. Available at http://www.epa.gov/ opptsfrs/publications/OPPTS_Harmonized/870_Health_ Effects_Test_Guidelines/Series/870-1100.pdf

US EPA (US Environmental Protection Agency) (2001) Biopesticides registration action document-Bacillus thuringiensis plant incorporated protectants. Available at http:// www.epa.gov/oppbppd1/biopesticides/pips/bt_brad.htm

USDA (United States Department of Agriculture) (2004) National nutrient database for standard reference, release 16-1. http://www.nal.usda.gov/fnic/foodcomp/cgi-bin/list_ nut_edit.pl

USDA APHIS (United States Department of Agriculture Animal and Plant Health Inspection Sevice) (2005a) Plant protection and quarantine strategic plan FY 2005-2009. Available at http://www.aphis.usda.gov/plant_health/down loads/PPQStrategicPlan2005-2009.pdf
USDA APHIS (United States Department of Agriculture Animal and Plant Health Inspection Sevice) (2005b) Introduction of organisms and products altered or produced through genetic engineering which are plant pests or which there is reason to believe are plant pests. Petition for determination of nonregulated status. 7CFR 340.6: 441-444. Available at http://edocket.access.gpo.gov/cfr_ 2005/janqtr/pdf/7cfr340.6.pdf

USEPA (US Environmental Protection Agency) (2004) Phosphomannose isomerase and the genetic material necessary for its production in all plants; exemption from the requirement of a tolerance. Fed Reg 69:26770-26775

van der Maarel MJEC, van der Veen B, Uitdehaag JCM, Leemhuis H, Dijkhuisen L (2002) Properties and applications of starch-converting enzymes of the $\alpha$-amylase family. J Biotechnol 94:137-155

Vazquez RI, Stinner BR, McCartney DA (2003) Corn and weed residue decomposition in northeast Ohio organic and conventional dairy farms. Agric Ecosyst Environ 95:559-565

Waldrop MP, Firestone MK (2004) Microbial community utilization of recalcitrant and simple carbon compounds: impact of oak-woodland plant communities. Oecologia 138:275-284

Wolt JD, Karaman S (2007) Estimated environmental loads of alpha-amylase from transgenic high-amylase maize. Biomass Bioenergy 31:831-835

Wolt JD, Peterson RKD (2000) Agricultural biotechnology and societal decision-making: the role of risk analysis. AgBioForum 3:39-46

Wolt JD, Keese P, Raybould A, Fitzpatrick JW, Burachik M, Gray A, Olin SS, Schiemann J, Sears M, Wu F (2009) Problem formulation in the environmental risk assessment for genetically modified plants. Transgenic Res. doi: 10.1007/s11248-009-9321-9 